\title{
in Vitro Effect of Methamphetamine on Proliferation, Differentiation and Apoptosis of Adipose Tissue Stem Cells
}

\author{
Leyla Anari ${ }^{1}$, Davood Mehrabani ${ }^{2,3,4,5}$, Mahboobeh Nasiri ${ }^{1}$, Shahrokh Zare ${ }^{2}$, Iman Jamhiri ${ }^{2}$, and Jason P. Acker ${ }^{5,6}$ \\ ${ }^{1}$ Department of Biology, Islamic Azad University, Arsanjan Branch, Arsanjan, Iran; ${ }^{2}$ Stem Cell Technology Research Center, \\ Shiraz University of Medical Sciences, Shiraz, Iran; ${ }^{3}$ Burn and Wound Healing Research Center, Shiraz University of Medical \\ Sciences, Shiraz, Iran; ${ }^{4}$ Comparative and Experimental Medicine Center, Shiraz University of Medical Sciences, Shiraz, Iran; \\ ${ }^{5}$ Department of Laboratory Medicine and Pathology, University of Alberta, Edmonton, AB, Canada; ${ }^{6}$ Innovation and Portfolio \\ Management, Canadian Blood Services, Edmonton, AB, Canada
}

Corresponding authors: Dr. Davood Mehrabani, Ph.D., Stem Cell Technology Research Center, Shiraz University of Medical Sciences, Shiraz, Iran; email: mehrabad@sums.ac.ir; Prof. Jason P. Acker, Ph.D., Centre for Innovation, Canadian Blood Services, Edmonton, AB, Canada; email: jacker@ualberta.ca

Received, August 31, 2021; Revised, November 15, 2021; Accepted, January 8, 2022; Published, January 12, 2022

\begin{abstract}
Purpose: Among abused substances, methamphetamine is a psychostimulant drug widely used recreationally with public health importance. This study investigated the effect of methamphetamine on proliferation, differentiation, and apoptosis of human adipose tissue stem cells (AdSCs). Methods: AdSCs were isolated from human abdominal adipose tissue and were characterized for mesenchymal properties and growth kinetics. MTT assay was undertaken to assess methamphetamine toxicity on proliferation and differentiation properties and apoptosis of hAdSCs. Results: Isolated cells were shown to have mesenchymal properties and a population doubling time (PDT) of $40.1 \mathrm{~h}$. Following methamphetamine treatment, expressions of KI-67 and TPX2 as proliferation genes and Col1A1 and PPAR $\gamma$ as differentiation genes decreased. Methamphetamine administration increased the expression of Bax and decreased Bcl-2 genes responsible for apoptosis. Conclusions: Our data suggested when AdSCs were exposed to methamphetamine, it decreased proliferation and differentiation properties of stem cells together with an increase in apoptosis. These findings can be added to the literature, especially when methamphetamine is used recreationally for weight loss purposes.
\end{abstract}

\section{INTRODUCTION}

Over the last decade, drug addiction has been designated as a costly, chronic, debilitating disease affecting several tissues (1). Among abused substances, methamphetamine is a psychostimulant drug widely used recreationally with public health importance inducing behavioral changes due to high level of methamphetamine-induced dopamine in the brain (2). Its low cost, high availability and easily synthesized in laboratories from inexpensive ingredients have made it an increasingly popular recreational drug worldwide. Its consumption enhances the release and also blocks the reuptake of dopamine producing euphoric effect lasting for 4 to $24 \mathrm{~h}(3,4)$.

Methamphetamine abuse can impair cognitive performance and it can cause neurotoxicity and neurodegenerative injuries (5) and lead to anxiety, emotional disorders, convulsions, and even death (6). It can be a strong risk factor for stroke, tachycardia, tachypnea, and hypertension (7). Methamphetamine can significantly influence basic homeostatic systems and protective functions resulting in enhancement of synaptic and extra-synaptic levels of serotonin, noradrenaline and dopamine leading to mitochondrial dysfunction, oxidative stress and inflammation that are responsible for several side effects (8).

Methamphetamine can induce hyperthermia and a potentially lethal rise in core body temperature, while this hyperthermia has a significant impact on thermogenic brown adipose tissue that may be responsible for the weight loss following methamphetamine use (9). The in vitro effect of various substances has previously been studied on mesenchymal stem cells (MSCs) including human adipose tissue stem cells (AdSCs) (10-13). Adipose tissue is an important source of MSCs, termed as adipose tissue-derived stem cells. They are easily obtained with little donor site morbidity making them an appropriate source in regenerative medicine. They were demonstrated to be immunoprivileged and 
genetically stable in long-term culture in comparison to bone marrow-derived stem cells (BMSCs) (14).

As methamphetamine users pose several challenges to centers providing alcohol and other drug evaluation, treatment, and healthcare, these centers expect a high rate of budget to present their services. Also, as methamphetamine is illegally used in different countries for various purposes such as alertness, enhancement of sexual pleasure, and weight loss (4), this study targeted in vitro effect of methamphetamine on growth kinetics, proliferation, apoptosis, and differentiation of human AdSCs to clarify the harms in these cells when weight loss is targeted in methamphetamine users.

\section{METHODS}

\section{Adipose Tissue Preparation}

Adipose tissue was provided from Department of Surgery, Shiraz University of Medical Sciences, Shiraz, Iran from the abdominal region of a 40-yearold man who underwent abdominoplasty and gave a written consent letter. All procedures of this study were in accordance with the rules of the institution Ethics Committee and the Helsinki Declaration on sampling tissues (IR.AIAU. 1395.6). The adipose tissue sample was transferred in a sterile Falcon tube (BD, USA) containing phosphate buffer saline (PBS, Sigma, USA) and one percent penicillin streptomycin (Sigma, USA) and fungisone (Sigma, USA). Quickly after sampling, the tube was taken to the cell culture laboratory of the Stem Cell Technology Research Center of Shiraz University of Medical Sciences, Shiraz, Iran. The tissue sample was washed several times with PBS to reach a clear fluid with adipose tissue sample.

\section{Isolation of Adipose-Derived Stem Cells}

After removing the PBS from the tube, the adipose tissue was chopped into small pieces and was treated with $5 \mathrm{~mL}$ of $0.2 \%$ collagenase enzyme type 1 (Sigma, USA) and placed in water bath at $37^{\circ} \mathrm{C}$ for 30 minutes, while the tube was stirred every 5 minutes. The specimen was centrifuged for $5 \mathrm{~min}$ at $1200 \mathrm{rpm}$ and the supernatant was removed, while the pellet was treated with $5 \mathrm{~mL}$ of Dulbecco's Modified Eagle Medium (DMEM, Biowest, France) to neutralize the enzyme. After passing through a 0.7 $\mu \mathrm{m}$ filter, the debris was removed and $5 \mathrm{~mL}$ of DMEM was added to the remained and spinning was undertaken again at $1200 \mathrm{rpm}$ for $5 \mathrm{~min}$.

The supernatant was taken out and the remained precipitate was resuspended in $1 \mathrm{~mL}$ of
DMEM and transferred into a culture flask containing $4 \mathrm{~mL}$ of DMEM supplemented with $10 \%$ fetal bovine serum (FBS, Gibco, USA), $1 \%$ glutamine, and $1 \%$ penicillin/streptomycin and the flasks were placed in an incubator at $37{ }^{\circ} \mathrm{C}$ with $5 \%$ $\mathrm{CO}_{2}$ and saturated humidity. The medium was changed every 3 days until $80 \%$ confluency. The cells were later harvested by $0.25 \%$ trypsin- EDTA (1X) (Gibco, USA) and subcultured to reach the $3^{\text {rd }}$ passage.

\section{Cell Characterization: Characterization by Morphology}

AdSCs were assessed morphologically using an invert microscope to be spindle shaped and adhered to the bottom of culture flasks. Images were captured for the cells by a digital camera (ELWD 0.3/OD75, Nikon, Tokyo, Japan) at different passages.

\section{Characterization by Flow Cytometry}

Flow cytometry was performed using a CyFlow CL (Partec, Münster, Germany) machine and aliquots of $5 \times 10^{5} \mathrm{AdSC}$ at $3^{\text {rd }}$ passage. Expression of surface markers was evaluated for expression of CD44 and CD90 as mesenchymal markers and expression of CD34 and CD45 as hematopoietic markers.

\section{Characterization by Osteogenic Differentiation}

Osteogenic induction was also performed to confirm mesenchymal properties of isolated cells. Briefly, 1 $\times 10^{4}$ AdSCs at $3^{\text {rd }}$ passage and $80 \%$ confluency were transferred into two $35 \mathrm{~mm}$ culture dishes (Corning, Germany) containing the control media of DMEMF12 (Bio West, France) supplemented with 10\% FBS, $1 \%$ penicillin/streptomycin and $1 \%$ Lglutamine (Sigma, USA). The osteogenic media consisted of DMEM-F12, $10 \%$ FBS, $1 \%$ penicillinstreptomycin, L-glutamine, $50 \mu \mathrm{g} / \mathrm{mL}$ L-ascorbic acid-2-phosphate (Merck, Germany), $100 \mathrm{nM}$ dexamethasone (Sigma, USA), and $10 \mathrm{mM} \beta$ glycerophosphate (Merck, Germany). The media was changed every 3 days. On day $21^{\text {st }}$, cultures were fixed with $70 \%$ ethanol for $15 \mathrm{~min}$ and then stained with $2 \%$ alizarin red S (Sigma, USA) and visualized under light microscope to confirm mineralization. Alizarin red staining binds to calcium ions in mineralized deposits leading to a brilliant red staining.

\section{Characterization by Adipogenic Differentiation}

For adipogenic differentiation, $1 \times 10^{4} \mathrm{AdSCs}$ at $3^{\text {rd }}$ passage and $80 \%$ confluency were seeded in two 35 $\mathrm{mm}$ culture dishes containing the control media of 
DMEM-F12 supplemented with $10 \%$ FBS, $1 \%$ penicillin/streptomycin and $1 \%$ L-glutamine and the adipogenic medium containing DMEM low glucose, $10 \%$ FBS, $100 \mathrm{nM}$ dexamethasone, $100 \mu \mathrm{M}$ ascorbic acid, and $200 \mu \mathrm{M}$ of indomethacin (Sigma, USA). The plates were maintained for 21 days and media change was conducted every 3 days. Finally, cells were fixed using a $10 \%$ formalin solution for 10 minutes and were subjected to Oil Red O (Sigma, USA) staining method, which specifically stained lipid droplets in red color.

\section{Population Doubling Time (PDT)}

To enumerate AdSCs, $3 \times 10^{4}$ cells $/$ per well at $3^{\text {rd }}$ passage were seeded into 24-well culture plates. The cell number was determined for 7 days after cell trypsinization, while 3 replicates were performed for each time point. AdSCs were stained by trypan blue (Sigma, USA) and quantified by a hemocytometer using a light microscope. The PDT, as the time required for a cell culture to be doubled in number, was evaluated by the formula of PDT $=\mathrm{T} \ln 2 / \ln (\mathrm{Xe}$ ( $\mathrm{Xb}$ ), as $\mathrm{T}$ was the incubation time in hours, $\mathrm{Xb}$ was the cell number at the beginning of the incubation time and Xe was the cell number at the end of the incubation time (15).

\section{Cell Viability}

Trypan blue exclusion test using $0.4 \%$ trypan blue in PBS was undertaken to assess the number of viable and nonviable cells.

\section{MTT Assay}

MTT assay was used to determine the toxicity of 2 different therapeutic doses of 6 and $60 \mu \mathrm{g} / \mathrm{mL}$ of methamphetamine (Sigma-Aldrich, USA) which are considered and described as recreational doses (16). These doses were exposed to AdSCs to determine the optimum dose regarding cell viability during $24 \mathrm{~h}$ in order to confirm the safe doses $(6$ and $60 \mu \mathrm{g} / \mathrm{mL})$. Before experiments, it was dissolved in normal saline. The dose $6 \mu \mathrm{g} / \mathrm{mL}$ of methamphetamine was added once and twice with a 6 hours interval and the dose $60 \mu \mathrm{g} / \mathrm{mL}$ identically was treated once and twice with 6-hour time interval too. The control untreated cells were incubated with culture medium for $4 \mathrm{~h}$. An MTT solution in $0.1 \mathrm{mM}$ phosphatebuffered saline (PBS) was added to each well for each sample, and the plates were incubated at $37{ }^{\circ} \mathrm{C}$ for 4 hours. Cells were enumerated for 10 days when $3 \times 10^{4}$ cells/per well at $3^{\text {rd }}$ passage were seeded into five wells of 12-well culture plates (One plate as control and 4 as methamphetamine treated cells). The experiments were repeated three times and each time with $3 \times 10^{4}$ cells of $3^{\text {rd }}$ passage per well (15).

\section{Gene Expression Analysis}

The total RNAs from the AdSCs were isolated by an RNA extraction kit (Cinnagen Inc., Iran) and RNA purity, integrity and concentration were assessed at optical density of $260 / 280 \mathrm{~nm}$ and using $1 \%$ agarose gel electrophoresis. The complementary DNA (cDNA) was provided based on manufacturer's guideline using $1 \mu \mathrm{g}$ RNA by RevertAid ${ }^{\mathrm{TM}}$ First Strand cDNA Synthesis kit (Fermentas Inc.). Real-time PCR was undertaken on an Applied Biosystems StepOne ${ }^{\mathrm{TM}}$ Instrument (ABI, Step One, USA) based on guidelines of RealQ Plus 2x Master Mix Green (Ampliqon Inc.). Real-time PCR for expression analysis of the primer pairs for GAPDH, Bax, Bcl-2, COL1A1, PPAR $\gamma$ KI-67 and TPX2 were designed and demonstrated in Table 1.

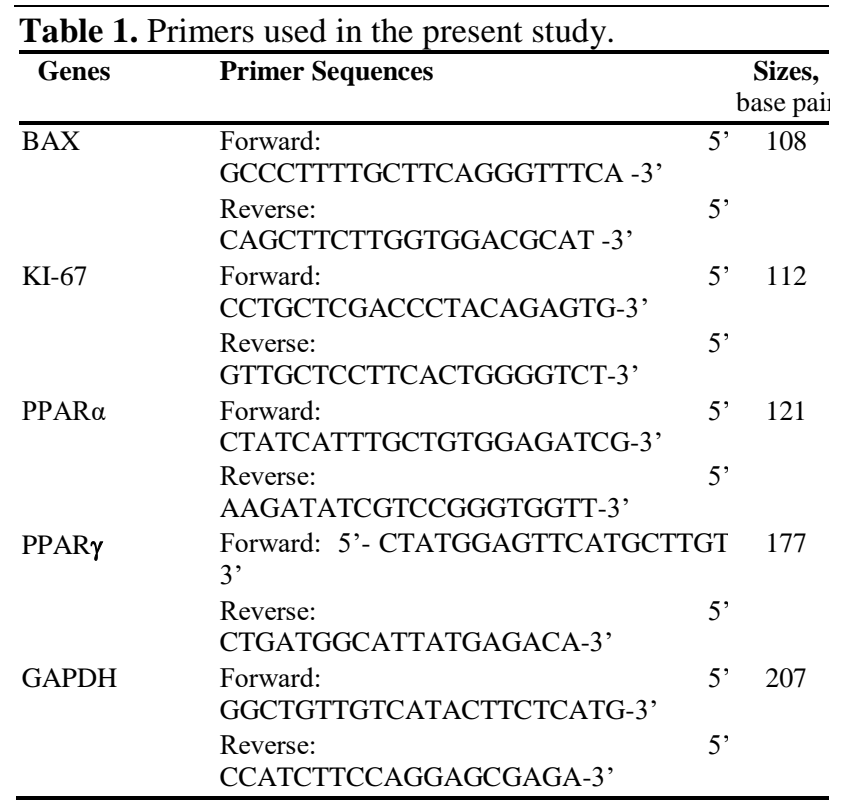

Real-time quantitative PCR machine was applied to determine the expression level of COL1A1, Bax and Bcl-2 genes in response to different doses of methamphetamine treatment. The GAPDH was the housekeeping gene and the internal control. The real-time PCR was set at $94{ }^{\circ} \mathrm{C}$ for 10 minutes followed by $94{ }^{\circ} \mathrm{C}$ for 40 cycles of 15 seconds, $60{ }^{\circ} \mathrm{C}$ for 60 seconds and extension steps. All reactions were performed in triplicate. After each run, gel electrophoresis and melting curve analysis were used to confirm specific amplification of targets. The amplification signals of different samples were normalized to GAPDH Ct (cycle 
threshold), and then delta-delta CT ( $\left.2^{-\Delta \Delta \mathrm{Ct}}\right)$ method to compare the mRNA level of test versus control represented as fold change in data analysis (15).

\section{DATA ANALYSIS}

The experiments were repeated three times and each time with $3 \times 10^{4}$ cells of $3^{\text {rd }}$ passage per well. This cell viability and metabolic activity data is presented as mean \pm SD of three independent experiments. As triplicate measures of each of the three samples were performed for the gene expression analysis, data is reported as mean \pm SEM. Findings were analyzed by the one-way analysis of variance (ANOVA with Tukey post-hoc analysis using Prism software (version 6.0, GraphPad Software Inc., San Diego, CA, USA). The $P$ value was considered statistically significant when it was $\leq 0.05$.

\section{RESULTS}

\section{Cell Characterization}

Seven days after seeding of cells at different passages (Passage 1-3), a fibroblast like, elongated, spindle shaped morphology was visible, and when the cells were visualized under a inverted microscope, they were adherent to the bottom of the culture flasks (Fig. 1A-1D). Analysis of Alizarin red staining illustrated osteogenic potential of AdSCs at $3^{\text {rd }}$ passage (Fig. $1 \mathrm{E})$. Adipogenesis of cells was shown by formation of lipid droplets stained with Oil Red O staining, 21 days after induction in red color, in comparison to the control (Fig. 1F). AdSCs were positive for expression of CD44 and CD90 as mesenchymal markers and negative for CD34 and CD45 expression as hematopoietic markers (Fig. 1G).

\section{Growth Kinetics}

Growth curve and PDT of AdSCs in absence of methamphetamine treatment were demonstrated in Figure 2 until 7 days. The PDT was $40.1 \mathrm{~h}$ revealing that the proliferation of AdSCs had an increasing trend until day $6^{\text {th }}$ and then a decline in cell number was noted.

\section{MTT Assay}

The doses of 6 and $60 \mu \mathrm{g} / \mathrm{mL}$ of methamphetamine used once and twice with $6 \mathrm{~h}$ time interval on AdSCs revealed a decreasing trend in cell proliferation till the $7^{\text {th }}$ day when compared to the control group. This decrease was more when methamphetamine was added twice per day and when the dose of methamphetamine increased from 6 to $60 \mu \mathrm{g} / \mathrm{mL}$ (Table 2).

Table 2. Applied different doses of methamphetamine to $3 \times 10^{4}$ AdSCs/per well at $3^{\text {rd }}$ passage in 24-well culture plates. Enumeration was undertaken 3 times for each time point during a period of 7 days.

\begin{tabular}{ccc}
\hline $\begin{array}{c}\text { METH } \\
\text { concentration } \\
(\boldsymbol{\mu M})\end{array}$ & $\begin{array}{c}\text { Viability (Mean } \\
\pm \text { SD) }\end{array}$ & P value \\
\hline 0.6 & $78.2 \pm 2.2$ & 0.0018 \\
1.2 & $76.1 \pm 2.6$ & 0.0018 \\
6 & $70.9 \pm 4.4$ & 0.0037 \\
12 & $70.8 \pm 5.2$ & 0.0061 \\
40 & $68.1 \pm 3.8$ & 0.0017 \\
60 & $67.3 \pm 3.1$ & 0.0009 \\
130 & $39.2 \pm 3.3$ & 0.0001 \\
\hline
\end{tabular}

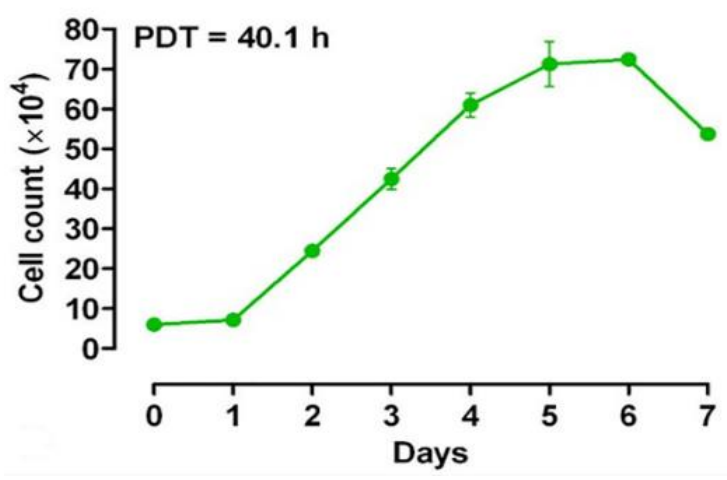

Figure 2. Growth curve and PDT of AdSCs isolated from human adipose tissue from three independent assays (mean $\pm \mathrm{SD} ; \mathrm{n}=3$ ).

\section{Gene Expression Analysis}

Regarding the expression of apoptotic genes, exposure to methamphetamine resulted to an increase in Bax expression of $1.13 \pm 0.12$-fold change for $6 \mu \mathrm{g} / \mathrm{mL}$ and $2.78 \pm 0.38$-fold change for $60 \mu \mathrm{g} / \mathrm{mL}$ of methamphetamine, $(P=0.01)$, and a decrease in BCL-2 expression of $0.83 \pm 0.049$-fold change for $6 \mu \mathrm{g} / \mathrm{mL}$ and $0.46 \pm 0.064$-fold change for $60 \mu \mathrm{g} / \mathrm{mL}$ of methamphetamine $(P=0.009)$ (Fig. 3A and $\mathrm{B})$. For differentiation gene of COL1A1, there was a decrease of $0.69 \pm 0.037$-fold change for 6 $\mu \mathrm{g} / \mathrm{mL}$ and a decline of $0.36 \pm 0.033$-fold change for $60 \mu \mathrm{g} / \mathrm{mL}$ of methamphetamine when AdSCs were treated with $((P<0.0001$ and $P<0.0001$, respectively) (Fig. 3C). The results for the PPAR $\gamma$ differentiation gene showed a significant 

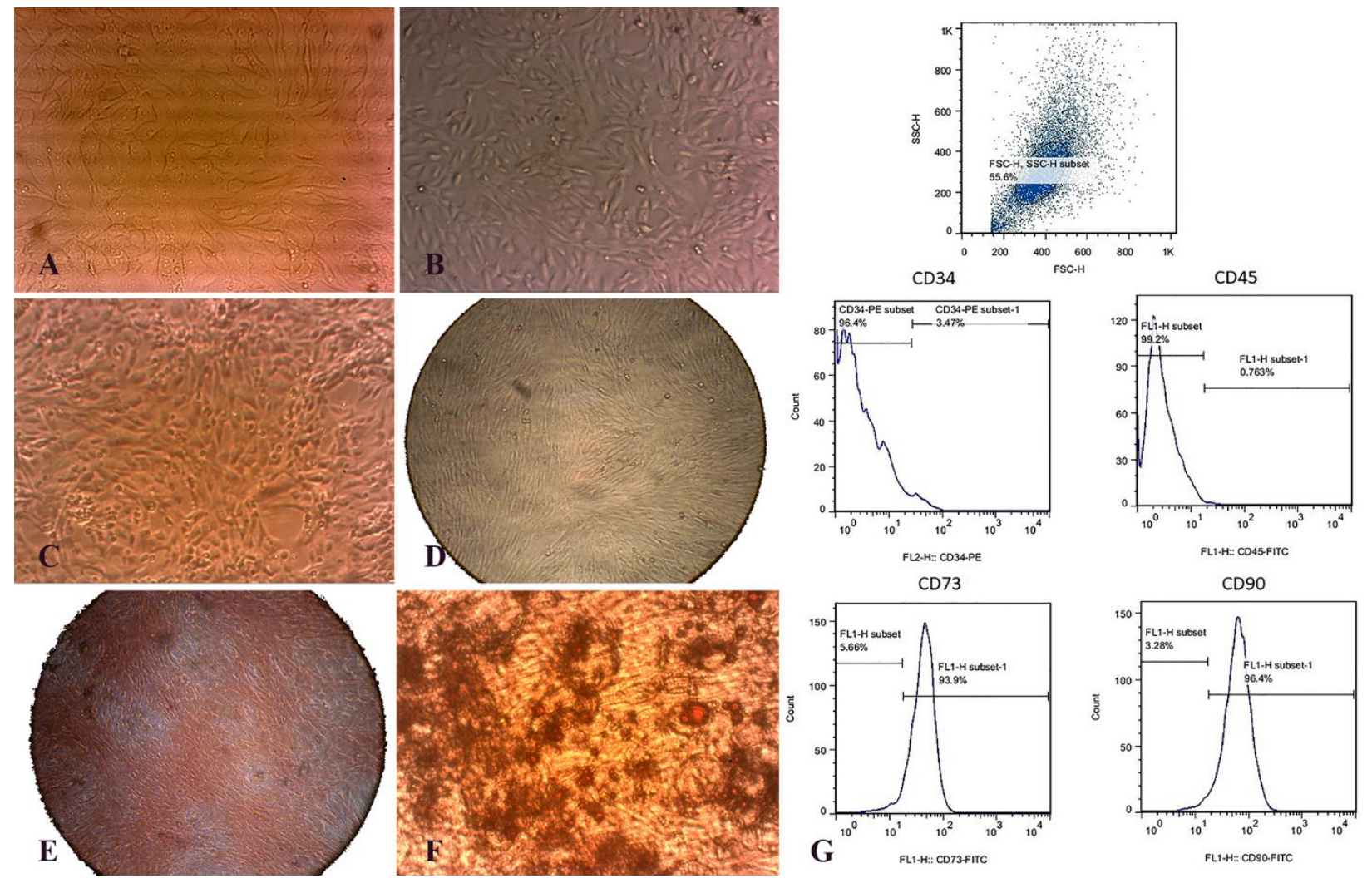

Figure 1. Morphology of human AdSCs. A: primary culture $(\times 40)$; B: First passage $(\times 40)$; C: $2^{\text {nd }}$ passage $(\times 40)$; and D: $3^{\text {rd }}$ passage $(\times 40)$. E: Analysis of alizarin red S staining and Oil Red O staining revealed osteogenic potential of AdSCs $(\times 40)$. F: Oil Red O staining denoted to adipogenic potential of the cells $(\times 40)$. G: Flowcytometry showed the cells to be negative for CD34 and CD45 and positive for CD44 and CD90.
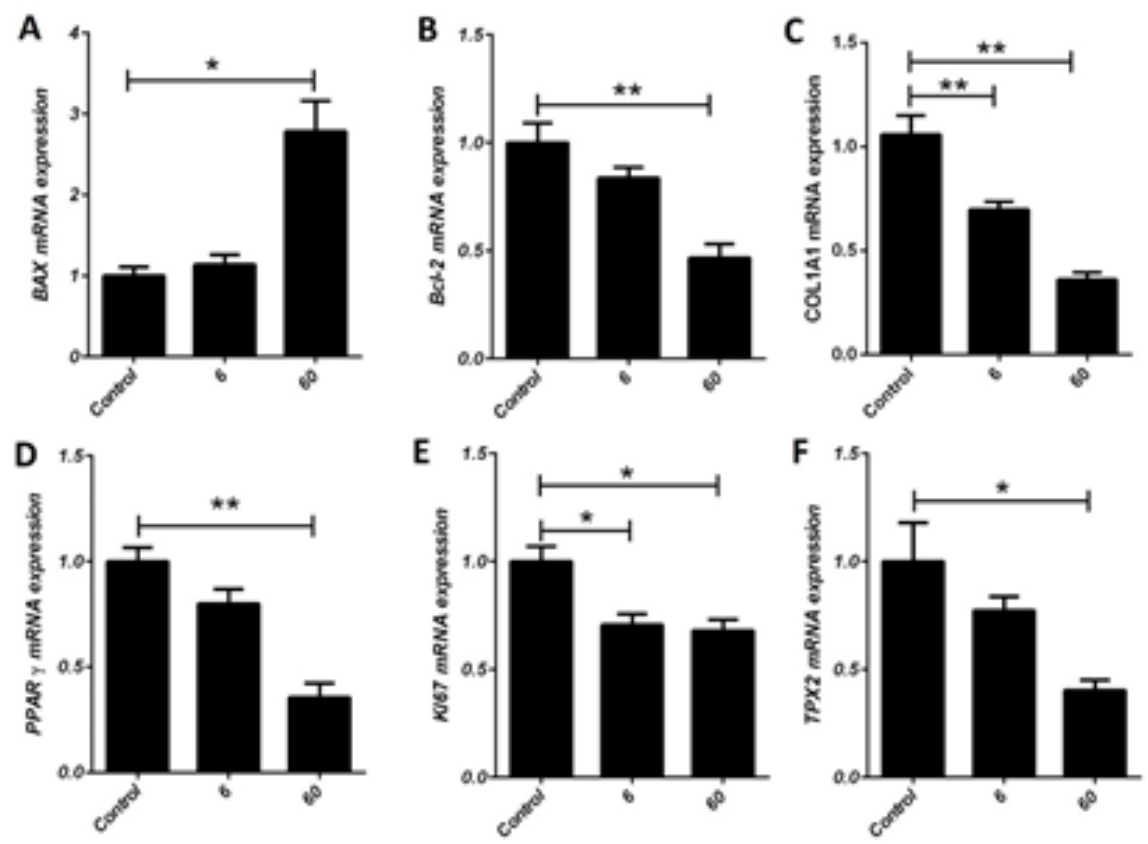

Figure 3. Using real-time quantitative PCR and assessment of the effect of 6 and $60 \mu \mathrm{g}$ methamphetamine on various genes: A: Bax, B: Bcl-2, C: COL1A1, D: PPAR $\gamma$, E: KI-67 and F: TPX2. Expression data relative to those of the reference gene are given from triplicate measures of three independent assays as mean \pm SEM. Statistical significance was defined as $* P$ value $<0.05$; and $* * P$ value $<0.01$. 
reduction in its expression as $0.8 \pm 0.07$-fold change for $6 \mu \mathrm{g} / \mathrm{mL}$ and $0.35 \pm 0.066$-fold change for 60 $\mu \mathrm{g} / \mathrm{mL}$ of methamphetamine $(P<0.05)$ (Fig. 3D). Methamphetamine was shown to decrease the expression of proliferation gene KI-67 as $0.7 \pm 0.05$ fold change for $6 \mu \mathrm{g} / \mathrm{mL}$ and $0.68 \pm 0.05$-fold change for $60 \mu \mathrm{g} / \mathrm{mL}$ of methamphetamine $(P=0.02$ and $P$ $=0.02$, respectively) (Fig. 3E) and the expression of proliferation gene of TPX2 when AdSCs were exposed to 6 and $60 \mu \mathrm{g} / \mathrm{mL}$ of methamphetamine, the fold change was $0.77 \pm 0.06$ and $0.40 \pm 0.04$, respectively $(P=0.03)($ Fig. $3 \mathrm{~F})$.

\section{DISCUSSION}

Methamphetamine or crystal belongs to a family of noncatecholamines, that when abused, it induces euphoria and alertness because of its long half-life action (6). In chronic methamphetamine abuses, anorexia, malnutrition, and weight loss happen and causes cell death in certain tissues (16). Methamphetamine-treatment of rat striatal cell line was shown to induce apoptosis via activating the mitochondrial cell death pathway (17). This induced cell loss was shown in mice substantia nigra too (18). It was found that methamphetamine can decrease the dentate gyrus stem cell population by delaying cell cycle and decreasing self-renewal capacities (19).

Methamphetamine can cause cellular apoptosis due to neurotoxicity and the involvement of autophagy and results in neuropathological dysfunction and irreversible brain damages $(20,21)$. Methamphetamine-treatment with human neuroblastoma cells (SH-SY5Y cells) exhibited excitotoxicity and an increase in oxidative stress and mitochondrial dysfunction that play a major role in the increase of Bax gene and death signaling cascade $(6,11,22,23)$. The BCL-2 family decreased $(6,11$, $22,23)$, which is another important regulator of apoptosis. The members of BCL-2 family are subdivided into two groups of anti-apoptotic, such as Bcl-2 and Bcl-XL, and pro-apoptotic including Bax and Bak proteins $(6,11,22)$. Similarly in our study, the expression of Bax increased and Bcl-2 decreased denoting an apoptotic effect of methamphetamine on AdSCs. Regarding the difference between two doses of methamphetamine, the low dose of $6 \mu \mathrm{g} / \mathrm{mL}$ reaches a plateau effect with a cell viability of $78.2 \%$. Utilizing the dose of $60 \mu \mathrm{g} / \mathrm{mL}$ changed the viability to $67.3 \%$ that did not show a significant difference, but when the dose of $130 \mu \mathrm{g} / \mathrm{mL}$ was utilized, a significant decrease in cell viability to $39.2 \%$ was noticed that was regarded a toxic dose for AdSCs treated with methamphetamine. Jamshidi et al. found an increase in apoptosis and a decrease in growth kinetics of AdSCs following cannabis use (23). Sazmand et al. reported identical results with an increase in apoptosis when BMSCs were subjected to cannabis (11).

Proliferation is a process in which the cell number increases as a result of cell growth and division to maintain the pool size of the progenitor cells. Since methamphetamine is a cationic lipophilic molecule, it can diffuse to the mitochondria via cellular membrane, leading to perturbation of normal mitochondrial function and mitochondrial toxicity (24). This creates a buildup of positively charged molecules inside the mitochondria and disturbs the electrochemical gradient of the electron transport chain which is needed for adenosine triphosphate (ATP) synthesis and mitochondrial membranes (25). These functions are necessary for cell survival, and failure in these functions initiates a signaling cascade, which results in cell death. Toxic effects of methamphetamine on embryonic stem cell (ESC)derived neurons were also shown before declining the outgrowth of dendrites in a dose dependent manner $(26,27)$. Identically in our study, AdSCs treated with methamphetamine were negatively affected by a decrease in proliferation genes of KI-67 and TPX2.

Histologically, it was shown that a significant increase in inflammation, degeneration and necrosis of adipose tissue happens in experimental rats after methamphetamine use (5). This toxic effect for methamphetamine on uterine tissue in rat animal model as uterine cysts was also described before (4). Change in blood chemistry, pro-inflammatory cytokines, and apoptotic genes following methamphetamine use was reported by several authors (6) that confirm our findings related to toxic effect of methamphetamine on AdSCs. The effect of methamphetamine on differentiation process was previously shown by Bento et al. (26). They presented the effect of methamphetamine on stem/progenitor cells obtained from early postnatal mice and found that methamphetamine inhibited neuronal differentiation, while the subventricular zone stem cells were more sensitive (26). Another study revealed that exposure to methamphetamine could result in a decreased and suppressed osteogenesis in MSCs (28). Identically in our study, a decrease in expression of COL1A1 and PPAR $\gamma$ for osteogenic and adipogenic differentiation were noted, when AdSCs were treated with methamphetamine. 
A limitation of this study was the inability to find any studies investigating methamphetamine effect on adipose tissue; however, this limitation provides opportunities for future research directions when targeting methamphetamine use for weight loss purposes. Future studies can consider non-healthrelated database sources and further explore the gray literature from conference proceedings too.

In conclusion, our data refer to a first study investigating the effect of methamphetamine on AdSCs at cellular and molecular levels regarding apoptosis, proliferation, and differentiation properties. These are important findings that can be added to the literature especially when targeting weight loss in methamphetamine users.

ACKNOWLEDGMENT. This article was derived from a master thesis of physiology and was approved by Islamic Azad University, Arsanjan Branch (IR.AIAU. 1395.6). I would like to thank Stem Cell Technology Research Center for their laboratory assistance.

COMPETING INTEREST. None to declare.

\section{REFERENCES}

1. Tabei SZ, Heydari ST, Mehrabani D, Shamsina SJ, Ahmadi J, Firouzi SM. Current substance use in patients with gastric cancer in southern Iran. J Cancer Res Ther. 2006; 2:11417. doi: 10.4103/0973-1482.29828.

2. Fogger SA. Methamphetamine use: A new wave in the opioid crisis? J Addict Nurs. 2019; 30:219-23.

doi: 10.1097/JAN.0000000000000298.

3. Bernheim A, See RE, Reichel CM. Chronic methamphetamine self-administration disrupts cortical control of cognition. Neurosci Biobehav Rev. 2016; 69:36-48. doi: 10.1016/j.neubiorev.2016.07.020.

4. Goudarzi Z, Hoseini SE, Mehrabani D, Hashemi SS, Derakhshanfar A, KarimiBusheri F. Effect of methamphetamine on uterine tissue, anxiety and apoptotic genes in female Wistar rats. Onl J Vet Res. 2020; 24:526-536.

5. Jaafari-Sheybani F, Hoseini SE, Mehrabani D, Derakhshanfar A, Karimi-Busheri F. Histological Changes in Adipose Tissue: An Alarm When Methamphetamine Is Targeted for Weight Loss Purposes. World J Plast Surg. 2021; 10:2-9. doi: 10.29252/wjps.10.1.53.
6. Goudarzi Z, Hoseini SE, Mehrabani D, Hashemi SS. Change in blood chemistry, proinflammatory cytokines, and apoptotic genes following methamphetamine use in experimental rats. Periódico Tchê Química 2020; 17:1147-1159.

doi: 10.52571/PTQ.v17.n36.2020.

7. Hassan SF, Wearne TA, Cornish JL, Goodchild AK. Effects of acute and chronic systemic methamphetamine on respiratory, cardiovascular and metabolic function, and cardiorespiratory reflexes. J Physiol. 2016; 594:763-80. doi: 10.1113/JP271257.

8. Bortell, N, Najera JA, Sanchez-Alavez M, Marcondes MC. In vivo effects of methamphetamine on brown fat reactive oxygen species and mitochondria. Temperature. (Austin). 2015; 2:453. doi: 10.1080/23328940.2015.1091874.

9. Rusyniak DE, Zaretsky DV, Zaretskaia MV, Durant PJ, DiMicco JA. The orexin-1 receptor antagonist SB-334867 decreases sympathetic responses to a moderate dose of methamphetamine and stress. Physiol Beh J. 2012; 107:743-50.

doi: 10.1016/j.physbeh.2012.02.010.

10. Jamshidi M, Hosseini SE, Mehrabani D, Amini M. Effect of hydroalcoholic extract of cannabis sativa on cell survival and differentiation of mesenchymal stem cells derived from human adipose tissue to osteoblast-like cells. J Gorgan Univ Med Sci. 2019; 21:50-8. [In Persian].

11. Sazmand M, Mehrabani D, Hosseini SE, Amini M. The effect of hydroalcoholic extract of Cannabis Sativa onmorphology and growth of bone marrow mesenchymal stem cells in rat. Electronic J Gen Med. 2018; 15:em32. doi:10.29333/ejgm/86195.

12. Parsa F, Hoseini SE, Mehrabani D, Hashemi SS, Derakhshanfar A. Effect of Cannabis sativa on brain tissue and memory in male Wistar rats. OL J Vet Res. 2020; 24:271-80.

13. Kamali-Sarvestani A, Hoseini SE, Mehrabani D, Hashemi SS, Derakhshanfar A. Effects in rats of adolescent exposure to Cannabis sativa on emotional behavior and adipose tissue. Bratisl Med J. 2020; 121:297-301. doi: 10.4149/BLL_2020_047.

14. Mehrabani D, Rabiee M, Tamadon A, Zare S, Razeghian Jahromi I, Dianatpour M, Khodabandeh Z. The growth kinetic, differentiation properties, karyotyping, and 
characterization of adipose tissue-derived stem cells in hamster. Comp Clin Pathol. 2016; 25:1017-22. doi: 10.1007/s00580-0162300-7.

15. Zare S, Mehrabani D, Jalli R, Saeedi Moghadam M, Manafi N, Mehrabani G, Jamhiri I, Ahadian S. MRI-Tracking of Dental Pulp Stem Cells In Vitro and In Vivo Using Dextran-Coated Superparamagnetic Iron Oxide Nanoparticles. J Clin Med. 2019; 8:E1418. doi: 10.3390/jcm8091418.

16. Pillai S, Cesarz B, Boulware C, Khan A. Hypotension, severe hyperthermia $\left(42^{\circ} \mathrm{C}\right)$, rhabdomyolysis, and disseminated intravascular coagulation induced by lethal dose of methamphetamine. Cureus. 2019; 11:e5245. doi: 10.7759/cureus.5245.

17. García-Cabrerizo R, Bis-Humbert C, GarcíaFuster MJ. Methamphetamine binge administration during late adolescence induced enduring hippocampal cell damage following prolonged withdrawal in rats. Neurotoxicology. 2018; 66:1-9. doi: 10.1016/j.neuro.2018.02.016.

18. Deng X, Cai NS, McCoy MT, Chen W, Trush MA, Cadet JL. Methamphetamine induces apoptosis in an immortalized rat striatal cell line by activating the mitochondrial cell death pathway. Neuropharmacology. 2002; 42:83745. doi: 10.1016/s0028-3908(02)00034-5.

19. Sonsalla PK, Jochnowitz ND, Zeevalk GD, Oostveen JA, Hall ED. Treatment of mice with methamphetamine produces cell loss in the substantia nigra. Brain Res. 1996; 738:172-5. doi: 10.1016/0006-8993(96)00995-x.

20. Baptista S, Lasgi C, Benstaali C, Milhazes N, Borges F, Fontes-Ribeiro C, Agasse F, Silva AP. Methamphetamine decreases dentate gyrus stem cell self-renewal and shifts the differentiation towards neuronal fate. Stem Cell Res. 2014; 13:329-41.

doi: 10.1016/j.scr.2014.08.003.

21. Yang G, Zeng X, Li J, Leung CK, Zhang D, Hong S, He Y, Huang J, Li L, Li Z. Protective effect of gastrodin against methamphetamineinduced autophagy in human dopaminergic neuroblastoma SH-SY5Y cells via the AKT/mTOR signaling pathway. Neurosci Lett. 2019; 707:134287. doi: 10.1016/j.neulet.2019.134287.

22. Wisessmith W, Phansuwan-Pujito P, Govitrapong P, Chetsawang B. Melatonin reduces induction of Bax, caspase and cell death in methamphetamine-treated human neuroblastoma SH-SY5Y cultured cells. J Pineal Res. 2009; 46:433-40. doi: 10.1111/j.1600-079X.2009.00680.x.

23. Jamshidi M, Hosseini SE, Mehrabani D, Amini M. Effect of hydroalcoholic extract of cannabis (cannabis sativa 1.) on morphology and the process of human adipose-drived mesenchymal stem cell growth. Electron $\mathbf{J}$ Gen Med. 2018; 15:em31. doi: 10.29333/ejgm/8458.

24. Wenlock MC, Potter T, Barton P, Austin RP. A method for measuring the lipophilicity of compounds in mixtures of 10 . J Biomol Screen. 2011; 16:348-55. doi: 10.1177/1087057110396372.

25. Bergman O, Ben-Shachar D. Mitochondrial oxidative phosphorylation system (OXPHOS) deficits in schizophrenia: possible interactions with cellular processes. Can J Psychiatry. 2016; 61:457-69.

doi: 10.1177/0706743716648290.

26. Bento AR, Baptista S, Malva JO, Silva AP, Agasse F. Methamphetamine exerts toxic effects on subventricular zone stem/progenitor cells and inhibits neuronal differentiation. Rejuvenation Res. 2011; 14:205-14. doi: 10.1089/rej.2010.1109.

27. Meamar R, Dehghani L, Karamali F. Toxicity effects of methamphetamine on embryonic stem cell-derived neuron. J Res Med Sci. 2012; 17:470-4.

28. Shen Y, Wu L, Wang J, Wu X, Zhang X. The role of mitochondria in methamphetamineinduced inhibitory effects on osteogenesis of mesenchymal stem cells. Eur J Pharmacol. 2018; 826:56-65.

doi: 10.1016/j.ejphar.2018.02.049. 